Check for updates

Cite this: RSC Adv., 2017, 7, 26211

\title{
Evaluation of the degree of chitosan deacetylation via induced-electrical properties
}

\author{
Dandan Li, ${ }^{\text {ab }}$ Lunan Guo, ${ }^{\text {ab }}$ Na Yang, (D) *ab Yao Zhang, ${ }^{\text {ab }}$ Zhengyu Jin ${ }^{\text {abc }}$ \\ and Xueming $\mathrm{Xu}(\mathbb{D}$ *abc
}

The properties and functionalities of chitosan are closely related to its degree of deacetylation (DD). This study aimed to determine the DD of chitosans, which were of identical molecular weight, by a proposed electro-analytical system based on inductive methodology. Statistically significant differences in electrical parameters, including terminal voltage $\left(U_{s}^{\prime}\right)$ and $\lambda$ (the ratio of primary voltage to $U_{s}^{\prime}$ ) were observed among chitosans with different DDs. Both $U_{S}^{\prime}$ and $\lambda$ were linearly correlated with the DD value, regardless of frequency, suggesting that these electrical parameters can be used to determine the DD of chitosan. More chitosan's coils contributed to higher measurement accuracy, but the change in measurement position showed no improvement. The highest linear coefficient of determination (0.9941) between DD and $U_{S}^{\prime}$ was obtained by the experimental transformer with 100-turn chitosan's coils at a primary voltage of $10 \mathrm{~V}$ and a frequency of $400 \mathrm{~Hz}$. This study explored the potential of an innovative electro-analytical system to determine the DD of chitosan.

Received 27th March 2017 Accepted 10th May 2017

DOI: $10.1039 / c 7 r a 03545 d$

rsc.li/rsc-advances polyelectrolyte when dissolved in an acidic aqueous solution, due to the protonation of amino groups on glucosamine units. ${ }^{17}$ The DD of chitosan is defined as the molar percent of $\beta-1,4-$ anhydroglucosamine in relation to the total $\beta-1,4-a n h y-$ droglucosamine and $N$-acetyl- $\beta$-1,4-anhydroglucosamine, ${ }^{11,17}$ which means that the DD value is closely related to the amino group content. Changing the amount of amino content, the electrical properties of chitosan acidic solutions change correspondingly. Therefore, the DD of chitosan can be determined through electrical techniques.

Electrical parameters are widely applied for the evaluation of the quality of agro-products and food, ${ }^{18,19}$ interfacial property of electrolyte solutions ${ }^{20}$ and characterization of membranes. ${ }^{21,22}$ Żywica et $a l .{ }^{23}$ suggested there was a linear correlation between total soluble solids in reconstituted apple juice and electrical parameters, which concluded that it is possible to evaluate the concentrations of apple purées in pulpy juices and beverages by electro-analytical method. Additionally, estimation of the quality of bighead carp (Aristichthys nobilis) during chilling storage $^{24}$ and determination of the degree of dispersion of fat globules in the homogenization process ${ }^{25}$ have also been successfully conducted by measuring electrical parameters. However, the electrical properties of agro-product, food, and other materials are usually determined by impedance, resistance, admittance, and conductance measurements via LCR meter, network analyzer, or impedance analyzer.

Therefore, electrical parameters represent quality factors of organic materials, such as fat content, ${ }^{26}$ fruit maturity, ${ }^{27}$ moisture content, ${ }^{28}$ even food adulteration. ${ }^{29}$ However, sophisticated instruments used in the existing electro-analytic methods is 
costly. Thus, further studies should assess material characteristics on the basis of measurable electrical properties via a lowcost system. Based on the transformer configuration, inducedelectrical detection system was established using liquid sample as a secondary coil. According to Faraday's effect, the varying magnetic flux in the primary coil induces a varying voltage in the secondary coil (sample's coil). When primary voltage $\left(U_{\mathrm{P}}\right)$ and the ratio of primary coil turn to secondary coil turn $\left(N_{\mathrm{P}} / N_{\mathrm{S}}\right)$ are constant, the induced voltage $\left(U_{\mathrm{S}}\right)$ do not alter according to Ampere's circuital theorem $\left(U_{\mathrm{S}} / U_{\mathrm{P}}=N_{\mathrm{S}} / N_{\mathrm{P}}\right)$. However, the changes in physicochemical properties of materials will affect the terminal voltage $\left(U_{s}^{\prime}\right.$, output voltage) in sample's closed-loop. Therefore, it is possible to use inducedelectrical parameter $U_{\mathrm{S}}^{\prime}$ to evaluate material characteristics. Our previous examinations have confirmed that physicochemical properties of liquid food can be estimated by determination of $U_{S}^{\prime}$ value $e^{30,31}$ and the induced-electrical detection system has a flexible and affordable configuration compared to other electro-detection systems. However, there has been no research on the assessment of physicochemical characteristics of organic materials via measurements of induced-electrical properties by changing turns ratio and using a two-series coil. Therefore, this study aimed to explore the potential of the proposed electroanalytical method as a general technique for the evaluation of chitosan DD. The correlation between DD of chitosans and induced-electrical parameters, including $U_{\mathrm{S}}^{\prime}$ and $\lambda$ value (the ratio of $U_{\mathrm{P}}$ to $U_{\mathrm{S}}^{\prime}$ ), was analyzed.

\section{Materials and methods}

\subsection{Materials}

Chitosan (DD $\geq 95 \%$ ) and acetyl-glucosamine were of analytical grade and were purchased from Aladdin Co., Ltd. (Shanghai, China). Acetic anhydride, sodium hydroxide, phosphoric acid, methanol, ethanol, and all other analytical chemicals were manufactured by Sinopharm Chemical Reagent Co., Ltd. (Suzhou, China).

\subsection{Preparation of chitosans with various DDs}

Chitosans with various DDs but the same $M_{\mathrm{w}}$, were obtained by homogeneous re-acetylation, as reported by Li et al. ${ }^{32}$ with slight modification. Chitosan (10 g) was first dissolved in $250 \mathrm{~mL} 2 \%$ $(\mathrm{w} / \mathrm{v})$ of aqueous acetic acid solution, and then $250 \mathrm{~mL}$ of methanol was added and magnetically stirred for $5 \mathrm{~min}$. After acetic anhydride was added slowly to the mixture at molar ratios of $1.05: 1,1.1: 1,1.2: 1,1: 1.4: 1,1.6: 1$, and $1.8: 1$, respectively, acetylation was performed by continuously stirring at $25{ }^{\circ} \mathrm{C}$ for $3 \mathrm{~h}$. Since chitosan only dissolves in dilute acid due to its cationic nature, the re-acetylated products were separated by adjusting the solution $\mathrm{pH}$ to 10 with $4 \mathrm{~mol} \mathrm{~L}^{-1} \mathrm{NaOH}$. The obtained white precipitates were collected through filtration under vacuum and washed with $80 \%$ ethanol four times $(300$ $\mathrm{mL}$ each time) to remove the residual $\mathrm{NaOH}$, unreacted reagents, and by-products. The filter cake was freeze-dried, and the obtained chitosans were used for further analysis.

\subsection{DD measurement}

The DDs of native and acetylated chitosans were determined using a first-derivative UV method, in which acetyl-glucosamine was utilized as standard. ${ }^{10}$ Chitosan $(100 \mathrm{mg})$ was dissolved in 20 $\mathrm{mL}$ of $85 \%$ phosphoric acid followed by continuous stirring at $60{ }^{\circ} \mathrm{C}$ for $40 \mathrm{~min}$. One milliliter of the mixture was then taken into a volumetric flask, and deionized water was added to the solution until a volume of $100 \mathrm{~mL}$ was reached. The diluted chitosan solution was then heated at $60{ }^{\circ} \mathrm{C}$ for $2 \mathrm{~h}$ and scanned using a UV-Vis spectrophotometer (TU-1900, Rayleigh Analytical Instruments, Beijing, China) under the scan mode and in the range from 220 to $190 \mathrm{~nm}$. Acetyl-glucosamine (100, 200, 300, 400 , and $500 \mathrm{mg}$ ) was weighed and added into the $100 \mathrm{~mL} 85 \%$ phosphoric acid. The solutions were then diluted with deionized water at a ratio of $100: 1 \mathrm{v} / \mathrm{v}$, treated at $60^{\circ} \mathrm{C}$ for $2 \mathrm{~h}$, and scanned at wavelengths in the range from 220 to $190 \mathrm{~nm}$. As a function of the concentrations of acetyl-glucosamine, a calibration curve was made by plotting the first derivative of the UV values at $203 \mathrm{~nm}$, and the DDs of the chitosans were calculated by using the calibration curve.

\subsection{Electrical conductivity measurement}

Chitosan solutions $(0.6 \% \mathrm{wt})$ were prepared by slow addition of the chitosans into $1 \%$ acetic acid and stirring at $25{ }^{\circ} \mathrm{C}$ for $24 \mathrm{~h}$. The electrical conductivity of the obtained solutions was measured using a conductivity meter (Mettler Toledo FE38Meter, Zürich, Switzerland) equipped with an electrode (Mettler Toledo LE703, Zürich, Switzerland) at $25{ }^{\circ} \mathrm{C}$.

\subsection{Viscosity measurement}

Chitosan (1.8 g) was slowly added into a $1 \%$ acetic acid solution $(300 \mathrm{~mL})$, and the mixture was magnetically stirred at $25{ }^{\circ} \mathrm{C}$ for $4 \mathrm{~h}$. Then, the viscosity of the chitosan-acetic acid solution was determined by a DV-C rotational viscometer (Brookfield, Middleboro, USA) using a spindle s61 at $100 \mathrm{rpm}\left(25^{\circ} \mathrm{C}\right)$.

\subsection{Molecular weight determination}

Molecular weight of chitosans was determined according to the high-pressure size-exclusion chromatography (HPSEC) method. The HPSEC separation was performed by two columns (Shodex OHpak SB-804 HQ and OHpak SB-802 HQ, Showa Denko America, Inc., New York, USA) connected in series with $0.2 \mathrm{~mol}$ $\mathrm{L}^{-1} \mathrm{CH}_{3} \mathrm{COOH} / 0.1 \mathrm{~mol} \mathrm{~L}^{-1} \mathrm{CH}_{3} \mathrm{COONa}(\mathrm{pH}=4.5)$ as the mobile phase at a flow rate of $0.6 \mathrm{~mL} \mathrm{~min}^{-1}$. The mobile phase was filtered through a $0.45 \mu \mathrm{m}$ syringe filter (Millipore, Billerica, Massachusetts, USA) and degassed by ultrasonic treatment for $30 \mathrm{~min}$. The column effluent was analyzed using a RI detector (Hitachi RI-5450, Hitachi, Tokyo, Japan). Samples were prepared as follows: chitosan $\left(4 \mathrm{mg} \mathrm{mL}^{-1}\right)$ was dissolved in the mobile phase at $25{ }^{\circ} \mathrm{C}$ for $24 \mathrm{~h}$, and then the obtained solution $(20 \mu \mathrm{L})$ was injected into the system. During the measurement, the temperature of columns was set up to $30{ }^{\circ} \mathrm{C}$. Pullulan standards (Shodex standard P-82) were used to calculate the weight-average molecular weight $\left(M_{\mathrm{w}}\right)$. 


\subsection{DD evaluation of chitosans based on inductive methodology}

The purpose of this electro-analysis was to determine the induced-electrical properties of chitosans with various DDs via electromagnetic induction. The schematic diagram and a photograph of the system are presented in Fig. 1. The system includes: (1) power source (PS-6105, Taiwan Pusi Electronics Co., Ltd., Taiwan); (2) circulating water bath (MP-10C, Yiheng Technical Co., Ltd., Shanghai, China); (3) AC millivoltmeter (UT631, UniTrend Group Limited Co., Ltd., Hong Kong, China); (4) platinum electrodes; (5) circulating water chamber; (6) glass chamber; (7) silicone steel core (no. PC80, cross-sectional area of the magnetic path $=40 \mathrm{~mm}^{2}$, length of the magnetic loop $=220 \mathrm{~mm}$; thickness of the magnetic path $=20 \mathrm{~mm}$ ); (8) primary coil. Copper conductor was wound on one side of the silicone steel core, acting as the primary coil $\left(N_{\mathrm{P}}=100\right)$, whereas the electroconductive solution was filled in a glass spiral tube (internal diameter of $3 \mathrm{~mm} ; N_{\mathrm{S}}=18$ ) or a polytetrafluoroethylene tube (internal diameter of $3 \mathrm{~mm} ; N_{\mathrm{S}}=100$ ) on the other side, acting as the secondary coil (chitosan's coil: chitosan acetic acid solution in the coil). Primary voltage applied on the primary coil generated an alternating magnetic flux in the core, leading to the induction of a voltage in the chitosan's coil. A pair of platinum electrodes connected to an AC millivoltmeter was employed to measure the $U_{\mathrm{S}}^{\prime}$ value in chitosan's coil. According to the principle of transformer $\left(U_{\mathrm{P}} / U_{\mathrm{S}}=N_{\mathrm{P}} / N_{\mathrm{S}}\right)$, as the $U_{\mathrm{P}}$ and $N_{\mathrm{P}} / N_{\mathrm{S}}$ were fixed, the $U_{\mathrm{S}}$ was a constant. However, the change of impedance will affect the $U_{\mathrm{S}}^{\prime}$ in the chitosan's circuit (chitosan acetic acid solution in the closed-loop). Therefore, this relationship could be used to characterize the DD value of chitosan by measuring their inducedelectrical parameters. In this study, three electro-analytical systems, including an experimental transformer $18\left(N_{\mathrm{S}}=18\right)$, transformer $100\left(N_{\mathrm{S}}=100\right)$, and a two-series transformer $\left(N_{\mathrm{S} 1}=\right.$ $N_{\mathrm{S} 2}=18$ ) were used. In the two-series system (Fig. 1b), the distance between two experimental transformers $\left(L_{\mathrm{bc}}\right)$ was 200 $\mathrm{mm}$.

Each chitosan $(0.6 \%(\mathrm{w} / \mathrm{v}))$ was prepared in $1 \%(\mathrm{w} / \mathrm{v})$ acetic acid at $25{ }^{\circ} \mathrm{C}$ for $24 \mathrm{~h}$ and injected into the coil with no air bubble. An excitation voltage (5-50 V and 300-700 Hz) generated by an AC power source was imposed on the primary coil. The measurement temperature was $25{ }^{\circ} \mathrm{C}$. The $U_{S}^{\prime}$ of the chitosan's coil were measured by an AC millivoltmeter. Another induced-electrical parameter $\lambda$ value was calculated. The regression models between $U_{\mathrm{S}}^{\prime}, \lambda$ value, and $\mathrm{DD}$ of chitosan were established.

\subsection{Statistical analysis}

Data were analyzed using the DPS package (version 8.0 for Windows, Hangzhou, China), and Fisher's least significant difference (LSD) test was applied to compare the differences between the means at $5 \%$ significance level. The correlation between DD of chitosan and measured electrical parameters ( $U_{\mathrm{S}}^{\prime}$ and $\lambda$ value) was determined using SPSS 16.0 software (Pearson's test). Linear regression was performed with Excel (Microsoft, 2011, Redmond, USA). The accuracy of the regression equation was assessed using coefficient of determination $\left(R^{2}\right)$ and root mean square error (RMSE).

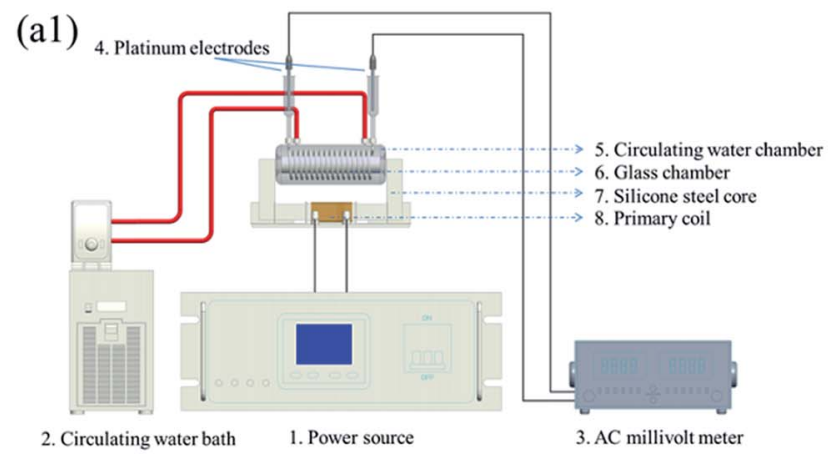

(a2)

(b1)
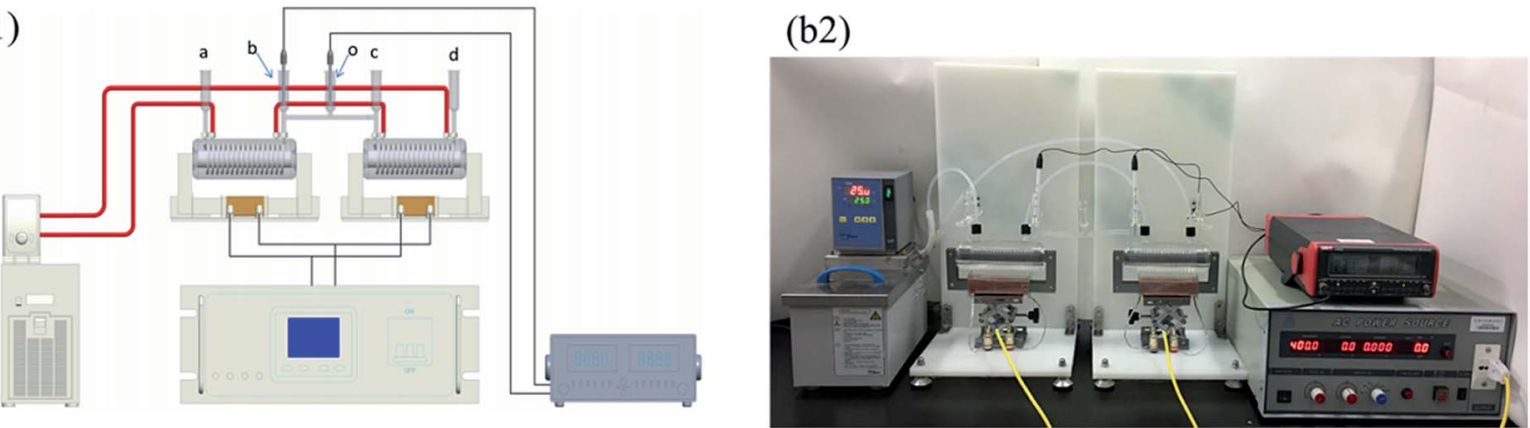

Fig. 1 The proposed electro-analytical system: (a1) the schematic diagram of a single system; (a2) the photograph of a single system; (b1) the schematic diagram of a two-series system; (b2) the photograph of a two-series system. 


\section{Results and discussion}

\subsection{Physicochemical properties of chitosans with various DDs}

The electrical conductivity of an electrolyte solution depends on ion concentration and its migration rate. ${ }^{33}$ In this study, chitosan samples $(1.8 \mathrm{~g})$ were dissolved in a $1 \%(\mathrm{v} / \mathrm{v})$ acetic acid solution $(300 \mathrm{~mL})$ at $25{ }^{\circ} \mathrm{C}$. The ion concentration was determined by the amount of the amino group, whereas ionic migration rate was related to the viscosity of the medium. Chitosans with identical molecular weight but differing DDs had similar viscosities (Table 1) but different amino group contents. Therefore, DD is the key factor that affects the conductivity of chitosan solutions. The increase of DD value from 53.56 to 99.83 resulted in a linear rise of the conductivity from 0.912 to $2.21 \mathrm{mS} \mathrm{cm}^{-1}\left(25{ }^{\circ} \mathrm{C}\right)$. A regression model, $y=37.422 x+15.385$, was obtained, indicating relatively high accuracy of the regression equation $\left(R^{2}=0.9514\right.$ and $\mathrm{RMSE}=3.90 \%$ ).

\subsection{Using terminal voltage and $\lambda$ value $\left(U_{\mathrm{p}} / U_{\mathrm{s}}^{\prime}\right)$ to evaluate DD of chitosan}

The current system exhibits a flexible configuration as the ratio of primary coil turn to secondary coil turn can be altered. Additionally, induced-electrical properties of organic materials have been investigated at various primary voltages and frequencies. ${ }^{34}$ These mean that statistical differences among these parameters can be reduced by altering the system configuration and detection conditions.

The induced-electrical parameters of the chitosan's circuit, including $U_{\mathrm{S}}^{\prime}$ and $\lambda$, were determined by transformer $18\left(N_{\mathrm{S}}=18\right)$ at a primary voltage of $20 \mathrm{~V}$ and a frequency from 300 to $700 \mathrm{~Hz}$. As shown in Fig. 2a, the DD value increased with the rise in $U_{\mathrm{S}}^{\prime}$ but slightly decreased with frequency augmentation for all samples. An opposite variation trend was observed in $\lambda$ values (Fig. 2b). At $300 \mathrm{~Hz}$, the $U_{\mathrm{S}}^{\prime}$ values of chitosan solutions with different DDs $(99.83,94.20,85.90,78.88,63.58,55.51$, and 53.56 ) were $2.21,1.968,1.889,1.833,1.432,1.08$, and 0.912 , while the $\lambda$ values were $9.23,9.66,10.16,10.32,11.35$, and 12.73, respectively. Higher differences were obtained during the measurement performed at $700 \mathrm{~Hz}$. Statistically significant differences among induced-electrical parameters $\left(U_{S}^{\prime}\right.$ and $\left.\lambda\right)$ of
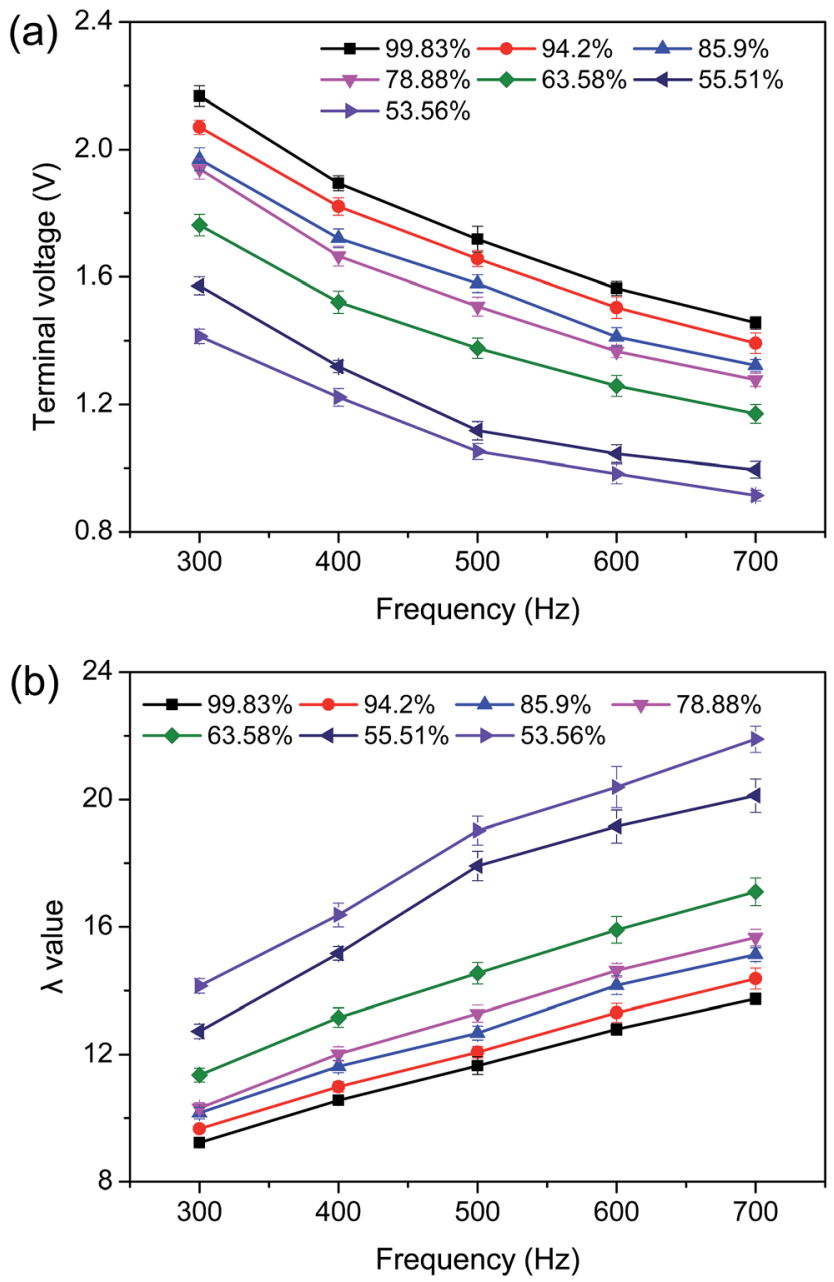

Fig. 2 Effects of frequency and DD on induced-electrical parameters determined by transformer 18 at $20 \mathrm{~V}$ primary voltage $\left(U_{\mathrm{P}}\right)$ : (a) terminal voltage $\left(U_{\mathrm{s}}^{\prime}\right)$; (b) $\lambda$ value $\left(U_{\mathrm{P}} / U_{\mathrm{s}}^{\prime}\right)$.

chitosans indicated that these parameters may be used as an indicator of chitosan DD.

As described before (Section 2.6), the induced voltage did not change $\left(U_{\mathrm{P}} / U_{\mathrm{S}}=N_{\mathrm{P}} / N_{\mathrm{S}}\right)$ as primary voltage and coil turns remained constants. However, the increase in the DD of chitosan elevated the amino group content, resulting in an increase of ion concentration and a decrease of the impedance in the

Table 1 Physicochemical properties of chitosan ${ }^{a}$

\begin{tabular}{|c|c|c|c|c|c|}
\hline No. & $\begin{array}{l}\text { Chitosan: acetic } \\
\text { anhydride }\left(\mathrm{mol} \mathrm{mol}^{-1}\right)\end{array}$ & $\mathrm{DD}(\%)$ & Conductivity $\left(\mathrm{mS} \mathrm{cm}^{-1}\right)$ & Viscosity (mPa s) & $M_{\mathrm{w}}\left(\times 10^{3} \mathrm{~g} \mathrm{~mol}^{-1}\right)$ \\
\hline 1 & - & $99.83 \pm 0.32 \mathrm{a}$ & $2.21 \pm 0.102 \mathrm{a}$ & $40.68 \pm 1.34 \mathrm{a}$ & $6.416 \pm 0.539 a$ \\
\hline 2 & $1: 1.05$ & $94.20 \pm 0.12 \mathrm{~b}$ & $1.968 \pm 0.073 b$ & $40.14 \pm 2.11 a$ & $6.627 \pm 0.135 a$ \\
\hline 3 & $1: 1.1$ & $85.90 \pm 0.29 c$ & $1.889 \pm 0.042 b$ & $39.44 \pm 1.32 \mathrm{a}$ & $6.234 \pm 0.032 \mathrm{a}$ \\
\hline 4 & $1: 1.2$ & $78.88 \pm 0.43 d$ & $1.833 \pm 0.056 \mathrm{~b}$ & $41.21 \pm 1.76 a$ & $6.744 \pm 0.452 \mathrm{a}$ \\
\hline 5 & $1: 1.4$ & $63.58 \pm 0.26 \mathrm{e}$ & $1.432 \pm 0.034 \mathrm{c}$ & $40.33 \pm 1.43 a$ & $6.346 \pm 0.982 \mathrm{a}$ \\
\hline 6 & $1: 1.6$ & $55.51 \pm 0.31 f$ & $1.08 \pm 0.063 \mathrm{~d}$ & $42.33 \pm 2.01 \mathrm{a}$ & $6.565 \pm 0.262 \mathrm{a}$ \\
\hline 7 & $1: 1.8$ & $53.56 \pm 0.34 \mathrm{~g}$ & $0.912 \pm 0.087 d$ & $40.32 \pm 2.11 \mathrm{a}$ & $6.987 \pm 0.463 a$ \\
\hline
\end{tabular}

${ }^{a}$ Means in the same column with different letter indicate significant difference $(P<0.05)$; DD: degree of deacetylation; $M_{\mathrm{w}}$ : molecular weight of chitosan. 
chitosan's coil. The reduced total impedance boosted the induced current in the chitosan's coil according to Ohm's law, in which the induced current was equal to the ratio of the induced voltage to the equivalent impedance of the chitosan's circuit. As a result, the change in DD caused variations in the $U_{\mathrm{S}}^{\prime}$ and $\lambda$ of the chitosan solution. However, it is important to note that the $U_{S}^{\prime}$ values of eggs ${ }^{30}$ and pickled cucumbers ${ }^{31}$ slightly increased with frequency elevation. This difference might have been caused by specific physicochemical properties of the samples.

The effects of the $U_{\mathrm{P}}$ on the $U_{\mathrm{S}}^{\prime}$ and $\lambda$ value determined by the experimental transformer $18\left(N_{\mathrm{S}}=18\right)$ at $400 \mathrm{~Hz}$ are presented in Fig. 3. The rise in $U_{\mathrm{P}}$ from 5 to $50 \mathrm{~V}$, led to a significantly increase in the $U_{\mathrm{S}}^{\prime}$ of all samples. In contrast, $\lambda$ value was reduced as the $U_{\mathrm{P}}$ increased. This result can be explained by Ampere's circuital theorem, in which induced voltage in the chitosan's coil is positively proportional to the $U_{\mathrm{P}}$. A similar result was observed in our previous study. ${ }^{30,31,34}$

These results demonstrated the potential of $U_{\mathrm{S}}^{\prime}$ and $\lambda$ as indexes for the evaluation of the DD of chitosan. The correlations between $U_{\mathrm{S}}^{\prime}, \lambda$ value, and DD were subsequently determined (Tables 2-5).

\subsection{Relationships between DD and terminal voltage and $\lambda$ determined by transformer 18 system}

As shown in Tables 2 and 3, correlation and linear regression analysis of DD as a function of changes in $U_{S}^{\prime}$ and $\lambda$ of chitosans showed that mathematical relationships described by the equation $Y=A \pm B X$ were observed within the range of $U_{\mathrm{P}}$ from 10 to $50 \mathrm{~V}$ and frequencies of 400 and $700 \mathrm{~Hz}$. As the $U_{\mathrm{P}}$ increased from 10 to $50 \mathrm{~V}$, correlation coefficient ranged from
0.911 to 0.985 at $\alpha<0.01,400$ and $700 \mathrm{~Hz}$, revealing that the DD value can be determined based on the measurements of $U_{S}^{\prime}$ and $\lambda$ at the tested frequencies. However, no correlation was observed between induced-electrical parameters and DD value of chitosan at a primary voltage of $5 \mathrm{~V}$. Additionally, at higher $U_{\mathrm{P}}$ $(40 \mathrm{~V}$ and $50 \mathrm{~V})$, correlation coefficient between the inducedelectrical parameters and DD was lower than that at lower $U_{\mathrm{P}}$, especially at $400 \mathrm{~Hz}$. The reason might be the measurement error of the voltmeter and electromagnetic interference produced by the power source, affected the accuracy. When the electro-analysis was performed at low excitation voltage (5 V), induced voltage in the chitosan's coil was low $(<0.6 \mathrm{~V})$, and thus the effect of measurement error was obvious. At high excitation voltage $(50 \mathrm{~V})$, however, the electromagnetic interference was significant. As a result, the most effective prediction model (DD $=259.12 U_{\mathrm{S}}^{\prime}-91.546, R^{2}=0.9701, \mathrm{RSME}=2.98$ ) for DD was obtained at a primary voltage of $10 \mathrm{~V}$ and a frequency of $700 \mathrm{~Hz}$.

Higher $R^{2}$ values $\left(0.9001<R^{2}<0.9701\right)$ and lower RMSE values $(2.98 \%<\mathrm{RMSE}<5.45 \%)$ were obtained for the negative linear regressions of DD on $U_{\mathrm{S}}^{\prime}$ value when compared to those for the $\lambda$ value $\left(0.8178<R^{2}<0.9608 ; 3.42 \%<\mathrm{RMSE}<7.36 \%\right)$, suggesting that $U_{\mathrm{S}}^{\prime}$ value may be more effective than $\lambda$ value for the estimation of chitosan DD. Our previous study indicated that $\lambda$ value fits better for the evaluation of moisture content in eggs, ${ }^{30}$ might have been caused by the different chemical compositions of the materials.

\subsection{Relationship between DD and terminal voltage determined by transformer 100 system}

With the increase in chitosan's coil turns, induced voltage in chitosan's coil increased. As a result, statistical differences
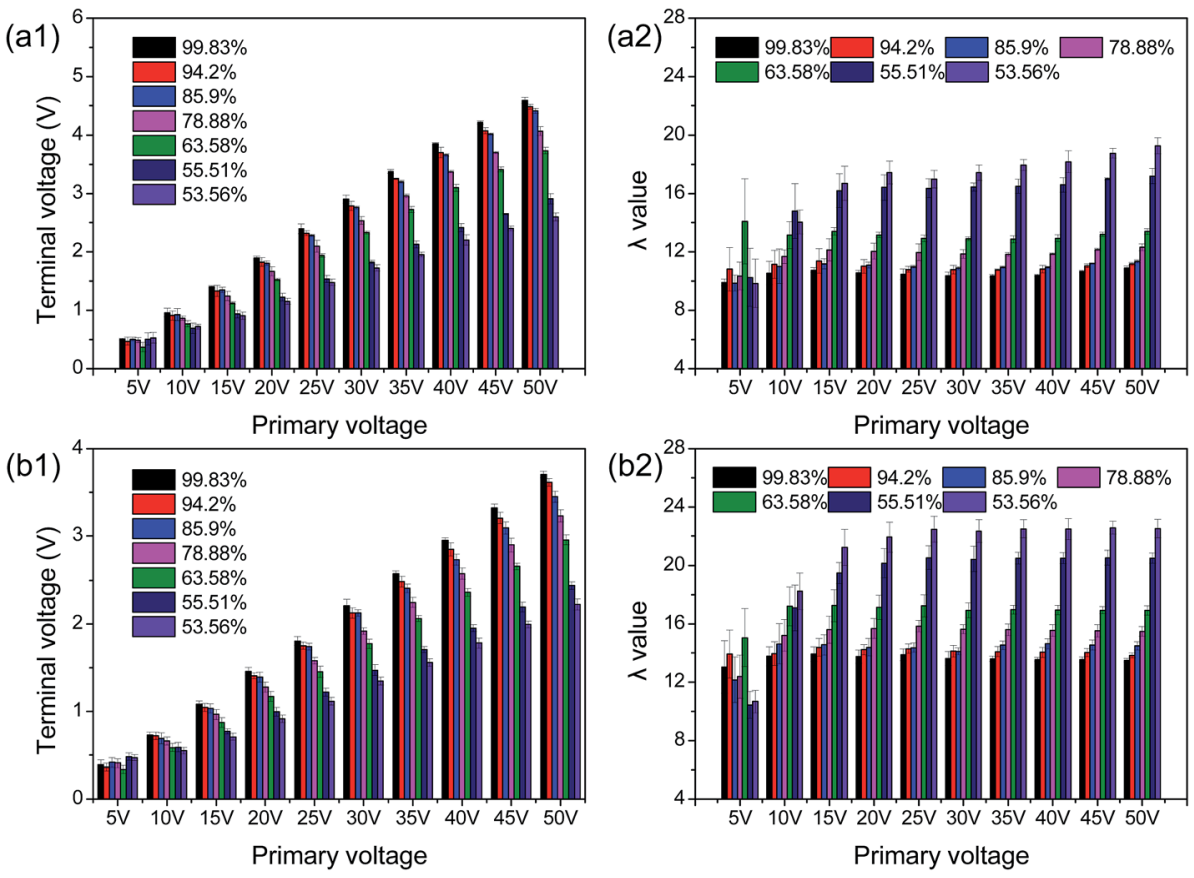

Fig. 3 Changes in terminal voltage $\left(U_{\mathrm{S}}^{\prime}\right)$ and $\lambda\left(U_{\mathrm{P}} / U_{\mathrm{S}}^{\prime}\right)$ determined by transformer 18 as affected by primary voltage at frequencies of $400 \mathrm{~Hz}$ and $700 \mathrm{~Hz}$ : (a1) terminal voltage, $400 \mathrm{~Hz}$; (a2) $\lambda$ value, $400 \mathrm{~Hz}$; (b1) terminal voltage, $700 \mathrm{~Hz}$; (b2) $\lambda$ value, $700 \mathrm{~Hz}$. 
Table 2 Correlation and regression analyses between degree of deacetylation (DD, \%) and terminal voltage $\left(U^{\prime}\right.$ s) determined by transformer $18^{a}$

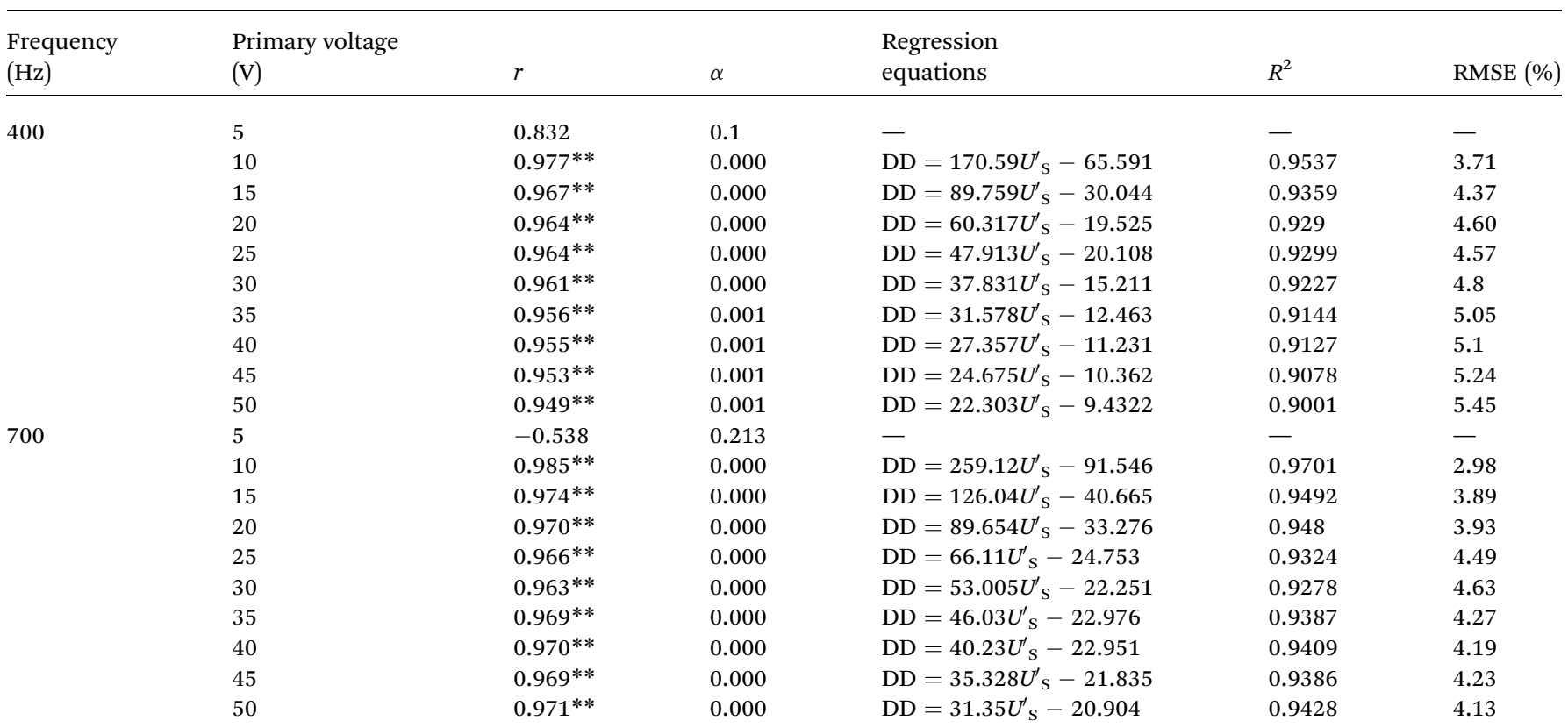

${ }^{a} r$, correlation coefficient; $\alpha$, significance level; ** significance of correlation $(\alpha \leq 0.01) ; R^{2}$, determination coefficient; RMSE represents root mean square error.

among the determined induced-electrical parameters of chitosan might be increased. Therefore, a system with 100-turn coil (transformer 100) was developed to determine the DD of chitosan.

At excitation voltage from 5 to $50 \mathrm{~V}$ and frequency ranging from 300 to $700 \mathrm{~Hz}$, the analysis between $\mathrm{DD}$ and $U_{\mathrm{S}}^{\prime}$ of chitosans demonstrated the presence of a correlation at a significance level of $\alpha<0.01$, with correlation coefficients ranging from 0.941 to 0.995 (Table 4). This suggested that relationships between DD and $U_{\mathrm{S}}^{\prime}$ in the tested ranges of $U_{\mathrm{P}}$ and frequency can be expressed by the equation $Y=A \pm B X$. Values

Table 3 Correlation and regression analyses between degree of deacetylation (DD, \%) and $\lambda$ value determined by transformer $18^{a}$

\begin{tabular}{|c|c|c|c|c|c|c|}
\hline $\begin{array}{l}\text { Frequency } \\
(\mathrm{Hz})\end{array}$ & $\begin{array}{l}\text { Primary voltage } \\
\text { (V) }\end{array}$ & $r$ & $\alpha$ & $\begin{array}{l}\text { Regression } \\
\text { equations }\end{array}$ & $R^{2}$ & RMSE (\%) \\
\hline \multirow[t]{7}{*}{400} & 5 & -0.234 & 0.614 & - & - & - \\
\hline & 15 & $-0.942^{* *}$ & 0.001 & $\mathrm{DD}=-7.1852 \lambda+170.04$ & 0.8883 & 5.77 \\
\hline & 20 & $-0.931^{* *}$ & 0.002 & $\mathrm{DD}=-6.2716 \lambda+158.08$ & 0.866 & 6.32 \\
\hline & 25 & $-0.933^{* *}$ & 0.002 & $\mathrm{DD}=-6.4468 \lambda+159.19$ & 0.8696 & 6.23 \\
\hline & 40 & $-0.914^{* *}$ & 0.004 & $\mathrm{DD}=-5.5325 \lambda+148.38$ & 0.8362 & 6.98 \\
\hline & 45 & $-0.911^{* *}$ & 0.004 & $\mathrm{DD}=-5.3162 \lambda+147.31$ & 0.8291 & 7.13 \\
\hline & 50 & $-0.904^{* *}$ & 0.005 & $\mathrm{DD}=-5.1106 \lambda+145.68$ & 0.8178 & 7.36 \\
\hline \multirow[t]{6}{*}{700} & 5 & 0.466 & 0.292 & - & - & - \\
\hline & 10 & $-0.980^{* *}$ & 0.000 & $\mathrm{DD}=-10.321 \lambda+238.22$ & 0.9608 & 3.42 \\
\hline & 15 & $-0.949 * *$ & 0.001 & $\mathrm{DD}=-6.2893 \lambda+180.52$ & 0.9011 & 5.52 \\
\hline & 40 & $-0.934^{* *}$ & 0.002 & $\mathrm{DD}=-5.0787 \lambda+161.33$ & 0.8721 & 6.17 \\
\hline & 45 & $-0.932^{* *}$ & 0.002 & $\mathrm{DD}=-5.0055 \lambda+160.09$ & 0.8688 & 6.25 \\
\hline & 50 & $-0.935^{* *}$ & 0.002 & $\mathrm{DD}=-4.9861 \lambda+159.44$ & 0.8738 & 6.13 \\
\hline
\end{tabular}

${ }^{a} r$, correlation coefficient; $\alpha$, significance level; ** significance of correlation $(\alpha \leq 0.01) ; R^{2}$, determination coefficient; RMSE represents root mean square error. 
Table 4 Correlation and regression analyses between degree of deacetylation (DD, \%) and terminal voltage $\left(U^{\prime}\right.$ s) determined by transformer $100^{a}$

\begin{tabular}{|c|c|c|c|c|c|c|}
\hline $\begin{array}{l}\text { Frequency } \\
(\mathrm{Hz})\end{array}$ & $\begin{array}{l}\text { Primary voltage } \\
\text { (V) }\end{array}$ & $r$ & $\alpha$ & Regression equations & $R^{2}$ & RMSE (\%) \\
\hline \multirow[t]{7}{*}{400} & 5 & $0.995 * *$ & 0.000 & $\mathrm{DD}=252.01 U_{\mathrm{S}}^{\prime}-128.29$ & 0.9771 & 1.41 \\
\hline & 15 & $0.981 * *$ & 0.003 & $\mathrm{DD}=36.756 U_{\mathrm{S}}^{\prime}+2.8066$ & 0.9625 & 2.17 \\
\hline & 20 & $0.978^{* *}$ & 0.004 & $\mathrm{DD}=21.23 U_{\mathrm{S}}^{\prime}+15.974$ & 0.9556 & 2.48 \\
\hline & 25 & $0.979 * *$ & 0.004 & $\mathrm{DD}=16.698 U_{\mathrm{S}}^{\prime}+16.48$ & 0.959 & 2.46 \\
\hline & 40 & $0.966^{* *}$ & 0.007 & $\mathrm{DD}=10.44 U_{\mathrm{S}}^{\prime}+18.39$ & 0.9334 & 3.28 \\
\hline & 45 & $0.968^{* *}$ & 0.007 & $\mathrm{DD}=9.5051 U_{\mathrm{S}}^{\prime}+18.567$ & 0.9369 & 3.09 \\
\hline & 50 & $0.981 * *$ & 0.003 & $\mathrm{DD}=9.2735 U_{\mathrm{S}}^{\prime}+16.373$ & 0.962 & 2.58 \\
\hline \multirow[t]{6}{*}{700} & 5 & $0.989 *$ & 0.011 & $\mathrm{DD}=101.21 U_{\mathrm{S}}^{\prime}-25.183$ & 0.9111 & 2.55 \\
\hline & 10 & $0.941^{*}$ & 0.017 & $\mathrm{DD}=109.9 U_{\mathrm{S}}^{\prime}-31.65$ & 0.9853 & 2.15 \\
\hline & 15 & 0.964 & 0.008 & $\mathrm{DD}=55.826 U_{\mathrm{S}}^{\prime}-1.3197$ & 0.9674 & 2.08 \\
\hline & 40 & $0.962 * *$ & 0.009 & $\mathrm{DD}=17.36 U_{\mathrm{S}}^{\prime}+12.122$ & 0.9447 & 2.37 \\
\hline & 45 & $0.960^{* *}$ & 0.010 & $\mathrm{DD}=15.934 U_{\mathrm{S}}^{\prime}+10.819$ & 0.9392 & 1.97 \\
\hline & 50 & $0.964^{* *}$ & 0.008 & $\mathrm{DD}=14.07 U_{\mathrm{S}}^{\prime}+11.76$ & 0.9519 & 2.28 \\
\hline
\end{tabular}

${ }^{a} r$, correlation coefficient; $\alpha$, significance level; * significance of correlation $(\alpha \leq 0.05) ; * *$ significance of correlation $(\alpha \leq 0.01) ; R^{2}$, determination coefficient; RMSE represents root mean square error.

of $R^{2}$ from 0.9334 to 0.9941 and of RMSE from $1.09 \%$ to $3.28 \%$ were established by evaluating mathematical correlations between DD and $U_{S}^{\prime}$ of the tested samples. The optimal model $\mathrm{DD}=123.44 U_{\mathrm{S}}^{\prime}-83.147$ with $R^{2}=0.9941$ and $\mathrm{RMSE}=1.09 \%$ was obtained at $10 \mathrm{~V}$ and $400 \mathrm{~Hz}$. These $R^{2}$ values were higher, whereas RMSE values were much lower, than those obtained by transformer 18 (Table 2). The reason might be the effects of electro-magnetic interference induced by the power source on induced-electrical parameters determination decreased as chitosan's coil turns increased. Therefore, $U_{\mathrm{S}}^{\prime}$ values measured by transformer 100 system were more precise to estimate the DD of chitosan because the utilization of magnetic flux was improved..$^{35}$

\subsection{Relationship between DD and terminal voltage determined by a two-series system}

As shown in Fig. 1a, $U_{S}^{\prime}$ and $\lambda$ obtained in parts 3.3 and 3.4 were determined by a pair of platinum electrodes connected to an AC millivoltmeter. During the measurement, electrodes were inserted into the chitosan's circuit under an alternating magnetic flux. To increase measurement accuracy, the determination position was changed. As can be seen in Fig. 1b, a detection system based on a two-series coil was developed, and induced-electrical parameter $U^{\prime}$ bo was determined (Table 5). Since the mutual induction exerted less pronounced effects on the measurement point "o", correlation coefficient between $U_{\text {bo }}^{\prime}$ and DD was expected to be higher. However, the $R^{2}$ values $\left(0.8429<R^{2}<0.9642\right)$ were lower than the values ob-

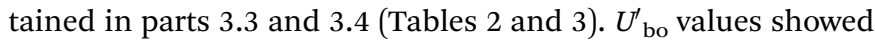
a trend that was opposite to that of $U_{\mathrm{S}}^{\prime}$ values, as determined by using the single-coil system (parts 3.3 and 3.4). The reduced $R^{2}$ values might be explained by the fact $U_{\text {bo }}^{\prime}$ values were much lower than the $U_{\mathrm{S}}^{\prime}$ values, caused by errors in voltmeter measurement. Therefore, the accuracy of the voltmeter had to be increased, or the electrical potential between position " $b$ " and "o" needed to be amplified. Theoretically, the voltage of the $U^{\prime}$ bo should be augmented with the increase of the distance between position " $b$ " and "o". In future, the influence of the length between position " $\mathrm{b}$ " and "o" $\left(L_{\mathrm{bo}}\right)$ on the correlation will be explored.

\subsection{Calibration of regression model}

According to the results obtained in parts 3.3, 3.4, and 3.5, regression models $\mathrm{DD}=259.12 U_{\mathrm{S}}^{\prime}-91.546$ and $\mathrm{DD}=123.44 U_{\mathrm{S}}^{\prime}$ - 83.147 were superior. These results were further assessed using a regression analysis of 20 samples which had DDs ranging from 55.55 to $99.83 \%$. The correlations between reference measurements (the first-derivative UV method) and predictions, which were obtained from optimal models, are shown in Fig. 4. All data points have clustered closely to the blue lines along the entire range of DD-values, which means that there is no systematic error present during the predictions. ${ }^{36}$ To better evaluate the models, residual values and RMSE were calculated. A homoscedasticity of the residual values was observed (Fig. 4c and d) and the RMSE had values as low as $1.99 \%$ and $2.18 \%$ for the two models, respectively. Thus, the optimized regression models were suitable to predict DD of chitosan. The proposed electro-analytical method has the potential to determine physicochemical properties of organic material. 
Table 5 Correlation and regression analyses between degree of deacetylation (DD, \%) and terminal voltage $\left(U^{\prime}\right.$ bo $)$ in the two-series system ${ }^{a}$

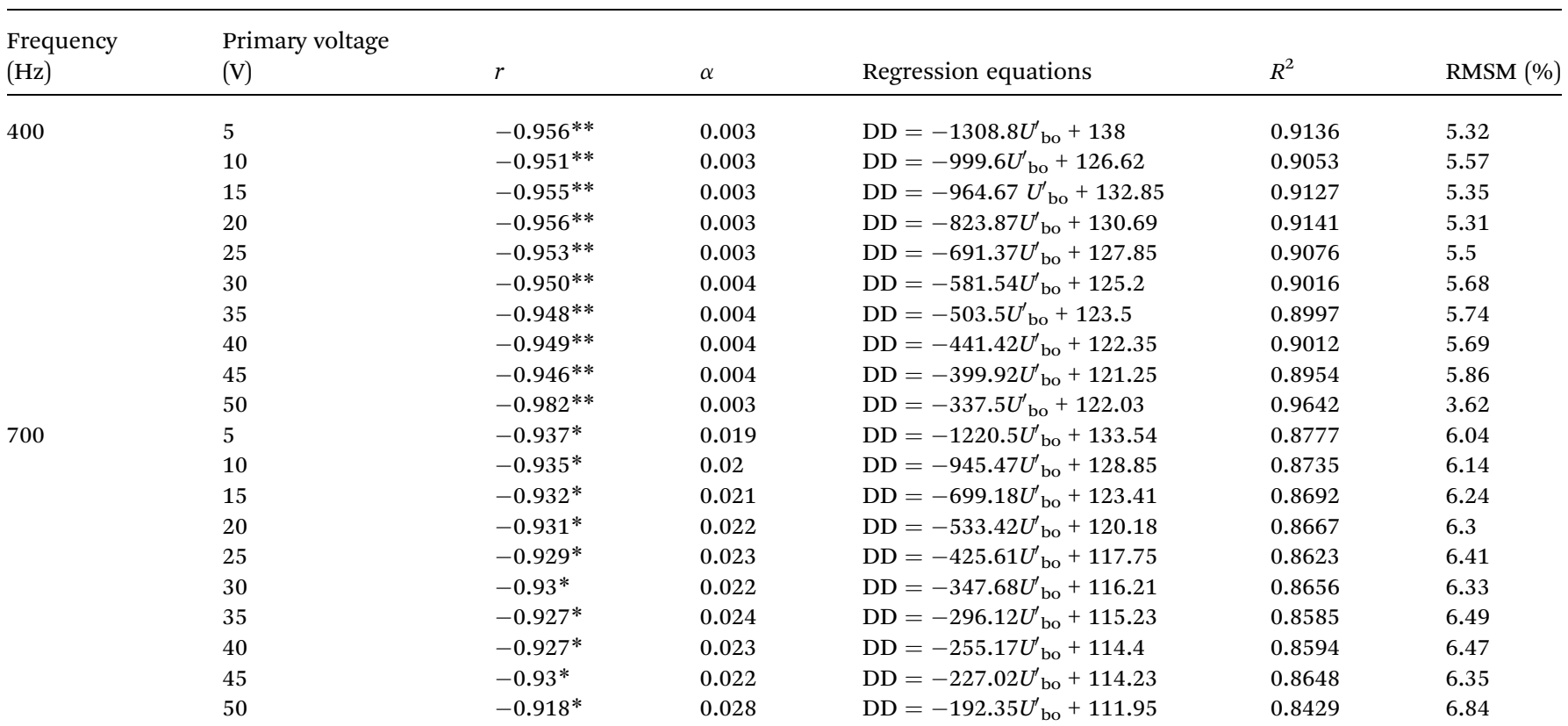

${ }^{a} r$, correlation coefficient; $\alpha$, significance level; * significance of correlation $(\alpha \leq 0.05) ; * *$ significance of correlation $(\alpha \leq 0.01) ; R^{2}$, determination coefficient; RMSE represents root mean square error.
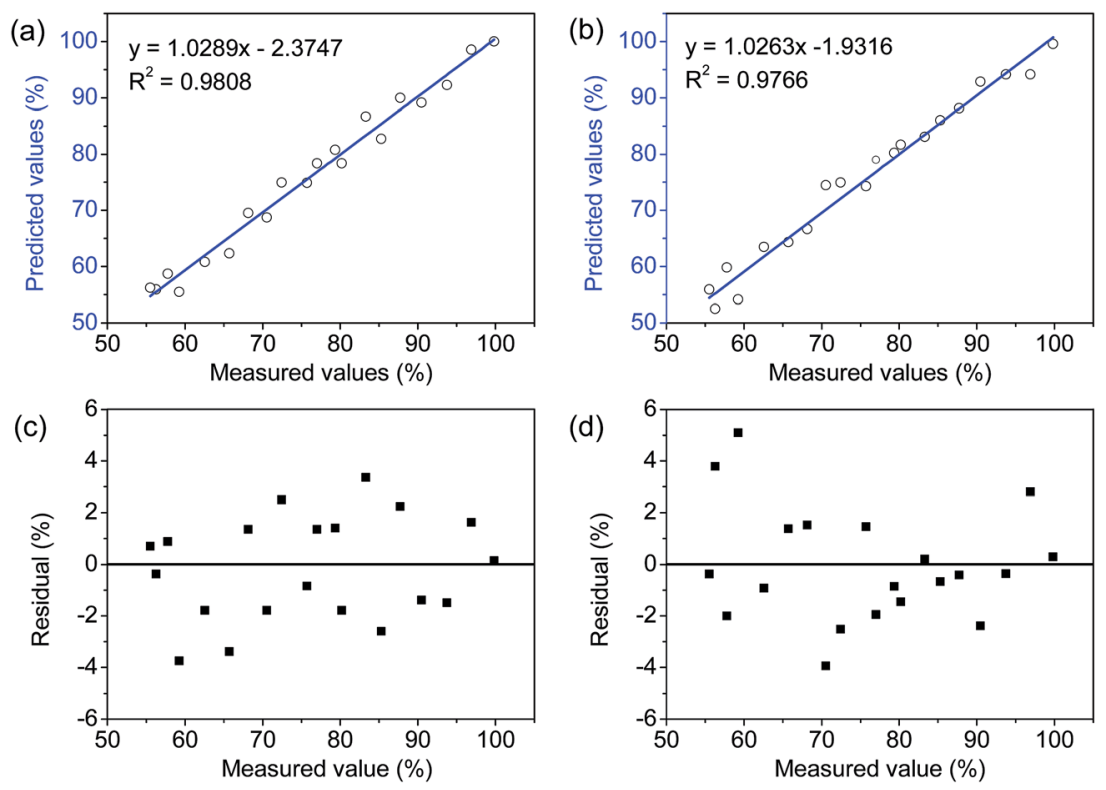

Fig. 4 Correlation plot of the predicted values ((a): obtained by the transformer 18 at $10 \mathrm{~V}$ and $400 \mathrm{~Hz}$; (b): obtained by transformer 100 at $10 \mathrm{~V}$ and $400 \mathrm{~Hz}$ ) and the residual values ((c): calculated from the regression model obtained by transformer 18 at $10 \mathrm{~V}$ and $700 \mathrm{~Hz}$; (d): calculated from the regression model obtained by transformer 100 at $10 \mathrm{~V}$ and $400 \mathrm{~Hz}$ ) versus the measured DD.

\section{Conclusion}

In this study, we evaluated the DD of chitosan with identical $M_{\mathrm{w}}$ by using inductive methodology. Induced-electrical parameters, such as $U_{S}^{\prime}$ and $\lambda$, were sensitive to the changes in the DD values because of changed amino group content. At constant of coil turn ratio $\left(N_{\mathrm{P}} / N_{\mathrm{S}}\right)$ and primary voltage, $U_{\mathrm{S}}^{\prime}$ continuously increased in linearly depending on the increase in DD values, regardless of frequency. The highest correlation coefficient (0.9941) was obtained at a $U_{\mathrm{P}}$ of $10 \mathrm{~V}$ and $400 \mathrm{~Hz}$. Although the change in the measurement position slightly decreased correlation coefficient between the induced-electrical parameter and DD values, coil turn ratio increased which was conducive to the measurement accuracy. The regression model suggests the 
feasibility of the electro-analytical method based on magnetoelectric coupling effect for evaluation of chitosan DD.

\section{Acknowledgements}

This work was financially supported by the Prospective Joint Research Project of Jiangsu Province (No. BY2016022-06) and the Graduate Student Innovation Project of Jiangsu Province (No. KYLX16_0820).

\section{References}

1 S. T. Koev, P. H. Dykstra, X. Luo, G. W. Rubloff, W. E. Bentley, G. F. Payne and R. Ghodssi, Lab Chip, 2010, 10, 3026-3042.

2 V. K. Thakur and M. K. Thakur, ACS Sustainable Chem. Eng., 2014, 2, 2637-2652.

3 A. Munoz-Bonilla, M. L. Cerrada and M. Fernandez-Garcia, in Polymeric Materials with Antimicrobial Activity: From Synthesis to Applications, The Royal Society of Chemistry, 2014, pp. 22-53, DOI: 10.1039/9781782624998-00022.

4 A. Smith, M. Perelman and M. Hinchcliffe, Hum. Vaccines Immunother., 2013, 10, 797-807.

5 T. Feng, Y. Du, J. Li, Y. Hu and J. F. Kennedy, Carbohydr. Polym., 2008, 73, 126-132.

6 S. K. L. Levengood and M. Zhang, J. Mater. Chem. B, 2014, 2, 3161-3184.

7 B. Moghadas, E. Dashtimoghadam, H. Mirzadeh, F. Seidi and M. M. Hasani-Sadrabadi, RSC Adv., 2016, 6, 7701-7711. 8 M. R. Kasaai, Carbohydr. Polym., 2008, 71, 497-508.

9 M. R. Kasaai, Carbohydr. Polym., 2010, 79, 801-810.

10 S. C. Tan, E. Khor, T. K. Tan and S. M. Wong, Talanta, 1998, 45, 713-719.

11 Z. M. dos Santos, A. L. P. F. Caroni, M. R. Pereira, D. R. da Silva and J. L. C. Fonseca, Carbohydr. Res., 2009, 344, 2591-2595.

12 Z. Han, Y. Zeng, H. Lu and L. Zhang, Carbohydr. Res., 2015, 413, 75-84.

13 L. S. Guinesi and É. T. G. Cavalheiro, Thermochim. Acta, 2006, 444, 128-133.
14 T. Sannan, K. Kurita and Y. Iwakura, Makromol. Chem., 1976, 177, 3589-3600.

15 L. Raymond, F. G. Morin and R. H. Marchessault, Carbohydr. Res., 1993, 246, 331-336.

16 X. Jiang, L. Chen and W. Zhong, Carbohydr. Polym., 2003, 54, 457-463.

17 C. Wu, C. Y. Kao, S. Y. Tseng, K. C. Chen and S. F. Chen, Carbohydr. Polym., 2014, 111, 236-244.

18 M. Xu, R. Wang and Y. Li, Talanta, 2016, 148, 200-208.

19 N. A. Karaseva and T. N. Ermolaeva, Talanta, 2012, 93, 44-48.

20 A. Trojánek, V. Mareček and Z. Samec, Electrochim. Acta, 2015, 179, 3-8.

21 K. Zhao, Q. Lu and W. Su, RSC Adv., 2014, 4, 63085-63099.

22 J. M. Spurgeon, M. G. Walter, J. Zhou, P. A. Kohl and N. S. Lewis, Energy Environ. Sci., 2011, 4, 1772-1780.

23 R. Żywica and J. K. Banach, J. Food Eng., 2015, 158, 8-12.

24 S. Zhu, Y. Luo, H. Hong, L. Feng and H. Shen, Food Bioprocess Technol., 2013, 6, 3068-3075.

25 M.-C. Michalski, F. Michel, D. Sainmont and V. Briard, Colloids Surf., B, 2002, 23, 23-30.

26 B. A. Lawton and R. Pethig, Meas. Sci. Technol., 1993, 4, 38. 27 S. O. Nelson, W. Guo and S. Trabelsi, 2008.

28 Z. Abbas, Y. You Kok, A. H. Shaari, K. Khalid, J. Hassan and E. Saion, IEEE Sens. J., 2005, 5, 1281-1287.

29 H. Lizhi, K. Toyoda and I. Ihara, J. Food Eng., 2010, 96, 167171.

30 N. Yang, Y. Jin, H. Wang, X. Duan, B. Xu, Z. Jin and X. Xu, J. Food Eng., 2015, 155, 45-52.

31 Y. M. Jin, N. Yang, Q. Ma, F. F. Wu, X. M. Xu and Q. Tong, Food Bioprocess Technol., 2015, 8, 749-757.

32 X. Li and W. Xia, Carbohydr. Polym., 2010, 82, 958-964.

33 R. A. Robinson and R. H. Stokes, Electrolyte solutions, Courier Corporation, 2002.

34 Y. Jin, N. Yang, X. Duan, F. Wu, Q. Tong and X. Xu, Biosystems Eng., 2015, 129, 70-77.

35 N. Yang, Y. Jin, D. Li, Z. Jin and X. Xu, Chem. Eng. J., 2017, 313, 599-609.

36 Z. Wu, E. Xu, J. Long, Y. Zhang, F. Wang, X. Xu, Z. Jin and A. Jiao, Food Control, 2015, 50, 405-412. 